BMJ Paediatrics Open

\title{
Characteristics of low-acuity paediatric emergency department consultations in two tertiary hospitals in Switzerland: a retrospective observational study
}

\author{
Manon Jaboyedoff (D , ${ }^{1}$ Carl Starvaggi, ${ }^{2}$ Joan-Carles Suris, ${ }^{1,3}$ Claudia E Kuehni, ${ }^{4}$ \\ Mario Gehri, ${ }^{1}$ Kristina Keitel, ${ }^{2}$ Rachel Pellaton ${ }^{1}$
}

To cite: Jaboyedoff M, Starvaggi C, Suris J-C, et al. Characteristics of lowacuity paediatric emergency department consultations in two tertiary hospitals in Switzerland: a retrospective observational study. BMJ Paediatrics Open 2021;5:e001267. doi:10.1136/ bmjpo-2021-001267

\section{- Additional supplemental material is published online only. To view, please visit the journal online (http://dx.doi.org/ 10.1136/bmjpo-2021-001267).}

$\mathrm{KK}$ and RP contributed equally.

Received 28 August 2021 Accepted 9 November 2021

Check for updates

\section{(c) Author(s) (or their} employer(s)) 2021. Re-use permitted under CC BY-NC. No commercial re-use. See rights and permissions. Published by BMJ.

For numbered affiliations see end of article.

\section{Correspondence to} Manon Jaboyedoff; manon. jaboyedoff@chuv.ch

\section{ABSTRACT}

Background Low-acuity paediatric emergency department (PED) visits are common in high-income countries and are an increasing burden for the healthcare system and quality of care. Little is known about lowacuity PED visits in Switzerland. This study shows frequency and characteristics of such visits in two large PEDs in German-speaking and French-speaking regions of Switzerland.

Methods We conducted a retrospective observational study in the PED of two Swiss tertiary care hospitals, Bern and Lausanne. We extracted standardised administrative and medical data from the clinic information system for all PED visits of children aged 0-17 years from January to December 2018. We defined low-acuity visits as those meeting all of the following criteria: (1) triage category 4 or 5 on the Australasian Triage Scale, (2) no imaging or laboratory test performed and (3) discharge home. We used a binary multiple logistic regression model to identify factors associated with low-acuity visits.

Results We analysed 53089 PED visits. The proportion of low-acuity visits was $54 \%$ (95\% Cl 53\% to 54\%, 28556 visits). Low-acuity visits were associated with age younger than 5 years (adjusted OR, aOR 1.87, 95\% $\mathrm{Cl} 1.81$ to 1.94 ), living within a $5 \mathrm{~km}$ radius of PED (aOR $1.27,95 \% \mathrm{Cl} 1.22$ to 1.32 ), and after hour presentations (weekends: $\mathrm{aOR}$ $1.14,95 \% \mathrm{Cl} 1.10$ to 1.18 , nights: aOR $1.10,95 \% \mathrm{Cl} 1.23$ to 1.36 ).

Conclusion Low-acuity visits are frequent in our PEDs and associated with younger age and convenience factors (proximity of residency and after hour presentation), pointing to a high demand for paediatric urgent care services in Switzerland not currently covered by the primary healthcare system.

\section{INTRODUCTION}

Low-acuity paediatric emergency departments (PEDs) visits are frequent, constituting up to three-quarters of all PED visits. ${ }^{1-3}$ Unscheduled medical consultations for non-life-threatening issues were traditionally provided by primary care providers in Switzerland. For children, paediatricians are the first-line providers of care with nearly $80 \%$ of all preschoolers regularly seeing a primary

\section{What is known about the subject?}

Low-acuity paediatric emergency department (PED) visits are common in high-income countries.

- Low-acuity PED visits have a negative impact on patient's care.

\section{What this study adds?}

- More than half of paediatric emergency department (PED) visits in Switzerland are low-acuity visits.

- Children younger than 5 years of age are more likely to visit PED for low-acuity reasons.

- Convenience factors (proximity of residency and after hour presentation) are associated with lowacuity PED visits.

care paediatrician. ${ }^{4}$ There is, however, an increasing recourse of families with sick children to EDs in high-income countries, including Switzerland. Here the incidence rate of PED visits is high with 438 PED visits per year per 1000 children younger than 6 years. ${ }^{5}$

Low-acuity PED visits have a negative impact on patient's care. At the individual level, each low-acuity PED visit is a missed opportunity for the children to meet their primary care provider and access to primary care resources. This may result in fragmented care, especially for children with chronic conditions. PED consultations are also stressful for children and their families. ${ }^{67}$ At the population level, low-acuity visits contribute to the overcrowding of PED which leads to delayed care, lower quality of care and higher costs. ${ }^{89}$

Little is known about the frequency and the characteristics of paediatric low-acuity visits in the Swiss PEDs. We investigated the number, proportion and factors associated with lowacuity visits in the PED of two tertiary-care 
hospitals in the German- and French-speaking regions of Switzerland, to provide insights to improve models of care for low-acuity PED visits.

\section{METHODS}

\section{Study design, participants and data source}

We conducted this retrospective observational study in the interdisciplinary surgical and medical PED of two tertiary-care hospitals, Bern University Hospital in the German-speaking part and Lausanne University Hospital in the French-speaking part of Switzerland. Both are the only PED in their region with over 50000 combined visits per year. Bern PED is a level 1 supraregional trauma centre for a combined rural and urban population of approximately 2 million. It is staffed $24 / 7$ by paediatric emergency medicine (PEM) specialists. It cares for over 20000 PED visits per year. Lausanne PED serves a population of over 1 million and is divided across two sites. The level 1 supraregional adult and paediatric referral trauma and burn centre is located in the main building of Lausanne University Hospital and cares for about 150 lifethreatening paediatric emergencies per year. ${ }^{10}{ }^{11}$ Most of the activity of Lausanne PED is located in another building and cares for the rest of paediatric emergencies, with over 30000 visits per year. It is staffed $24 / 7$ by paediatricians and PEM specialists.

Private practice paediatricians are the first-line providers of care for children in Switzerland. Public PEDs open 24/7 are present in all major cities and freely accessible to all. PED medical charges are covered by the compulsory health insurance for children.

The study period covers all visits that occurred over 1 year, from 1 January 2018 to 31 December 2018. We included all visits of children and adolescents aged 0-17 years. We extracted standardised administrative and medical data from the clinic information systems of both hospitals for all PED visits that occurred in 2018. Extractions were performed by the Information Technology department of each hospital. Data extracted included demographic variables (birth date and sex), administrative data (residency zip code, date and time of consultation), triage level, laboratory analyses and imaging. Multiple consultations within a 24-hour period were counted as one visit (the highest acuity triage score was considered for analysis).

\section{Outcome}

The primary outcome of our study was the acuity of PED visit. There is no consensus in the literature on the definition of low-acuity PED visits. ${ }^{12}$ Published studies used either one or a combination of criteria including triage level, diagnosis, resources used and disposition. We chose to define acuity as a combination of urgency and complexity of the PED visits. We used triage level as a measure of urgency and use of resources and disposition for complexity. Thus, we defined low-acuity visits as those which completed all of the following criteria: (1) triage level 4 or 5 on Australasian Triage Scale (ATS), ${ }^{13}$ (2) neither imaging nor laboratory testing performed and (3) discharge home. We also used a simpler definition of low-acuity where we defined a low-acuity visit as a visit with a triage level 4 or 5 . ATS levels 4 and 5 are not defined as low acuity within the scale itself. We chose this threshold because it represents the less acute visit and is used in other studies. ${ }^{31415}$ Since procedures, such as wound repairs, are not standardised in the electronic documentation system, they were not considered for the outcome definition.

\section{Explanatory variables}

We considered age, sex, distance between residency zip code and PED, and time of visit as possible determinants of low-acuity PED visits, based on previous studies. ${ }^{12}$ Close residency was defined as living in a postal code area distant less than $5 \mathrm{~km}$ from the PED.

\section{Statistical analysis}

We present results as point prevalence or median in the bivariate analysis exploring the differences between lowacuity and high-acuity consultations. We used Pearson's $\chi^{2}$ for categorical and Mann-Whitney $U$ test for continuous variables. To identify factors associated with lowacuity visits, all statistically significant variables $\mathrm{p}<0.05$ at the bivariate level were included in a binary multiple logistic regression model including baseline characteristics (gender, site). We performed sensitivity analysis with a different definition of low-acuity, and with the exclusion of neonates whose visits are classified as high-acuity per our definition, as they get an ATS of 3 or below. We performed all analyses using STATA (StataCorp. 2019. Stata Statistical Software: Release V.16., StataCorp).

\section{RESULTS}

\section{Characteristics of study population}

We extracted the data of 32170 PED visits in Lausanne and 23413 PED visits in Bern for the year 2018. We analysed 53089 PED visits, after exclusion of visits of patients 18 years and older (15 visits in Bern, 23 in Lausanne), visits with missing data (48 visits in Bern, 628 in Lausanne) and scheduled follow-up visits (1780 in Bern) (flow chart in online supplemental appendix 1).

Most children visiting our PEDs were younger than 6 years (table 1 ). The median age of children visiting our PEDs was 4 years (IQR 0.5-7.5). A minority of visits $(23 \%)$ had a high urgency triage (ATS 1-3). Imaging or laboratory studies were performed for less than a fifth of visits. Eleven percent of PED visits led to a hospital admission. More than half of the visits $(57 \%)$ were from patients living close to the PED. A majority (63\%) of PED visits happened outside business hours (evenings, nights or weekends). Winter months (December to March) had the highest number of visits per month while summer holidays months (July and August) the lowest. A higher 
Table 1 Characteristics of PED visits

\begin{tabular}{|c|c|c|c|}
\hline Characteristics & All PED visits, $\mathrm{N}=53089$ & Lausanne PED visits, $\mathrm{N}=\mathbf{3 1 5 1 9}$ & Bern PED visits, $\mathbf{N}=\mathbf{2 1 5 7 0}$ \\
\hline Median age (years, IQR) & $4(0.5-7.5)$ & $4(0.05-7.9)$ & $3.6(0.2-7)$ \\
\hline Age: $<1$ month & $849(2 \%)$ & $356(1 \%)$ & $493(2 \%)$ \\
\hline Age: $1-11$ months & $7615(14 \%)$ & $4049(13 \%)$ & $3566(17 \%)$ \\
\hline Age: $12-23$ months & $7262(14 \%)$ & $4110(13 \%)$ & $3152(15 \%)$ \\
\hline Age: 2-5years & $16051(30 \%)$ & $9406(30 \%)$ & $6645(31 \%)$ \\
\hline Age: $6-11$ years & $13208(25 \%)$ & $8116(26 \%)$ & $5092(24 \%)$ \\
\hline Age: $12-17$ years & $8104(17 \%)$ & $5482(17 \%)$ & $2622(12 \%)$ \\
\hline Gender: female & 24201 (46\%) & $14519(46 \%)$ & $9682(45 \%)$ \\
\hline ATS 1 & $180(0 \%)$ & $6(0 \%)$ & $174(1 \%)$ \\
\hline ATS 2 & $3181(6 \%)$ & $765(2 \%)$ & $2416(11 \%)$ \\
\hline ATS 3 & $8776(17 \%)$ & $3150(10 \%)$ & $5626(26 \%)$ \\
\hline ATS 4 & $15356(19 \%)$ & $6535(21 \%)$ & $8821(41 \%)$ \\
\hline ATS 5 & $25596(48 \%)$ & $21063(67 \%)$ & $4533(21 \%)$ \\
\hline Imaging performed & 10307 (19\%) & $5192(16 \%)$ & $5115(24 \%)$ \\
\hline Laboratory study performed & $9830(19 \%)$ & $4129(13 \%)$ & $5701(26 \%)$ \\
\hline Admissions & $5842(11 \%)$ & $2774(9 \%)$ & 3068 (14\%) \\
\hline Week-end visits & $16656(31 \%)$ & $9920(31 \%)$ & $6736(31 \%)$ \\
\hline Evening visits (18:00-21:00 hours) & $14379(27 \%)$ & $7924(25 \%)$ & $6455(30 \%)$ \\
\hline Night visits (22:00-8:00 hours) & $9195(17 \%)$ & $4984(16 \%)$ & $4211(20 \%)$ \\
\hline Residency $<5 \mathrm{~km}$ from PED & $30112(57 \%)$ & $23096(73 \%)$ & $7016(33 \%)$ \\
\hline Low-acuity PED visits & $28556(54 \%)$ & $19490(62 \%)$ & $9066(42 \%)$ \\
\hline
\end{tabular}

Values are median (IQR) or number (\%).

Definition of low-acuity visits: Triage ATS 4 or 5 , no laboratory nor imaging tests and no hospital admission.

ATS, Australasian Triage Scale; PED, paediatric emergency department.

proportion of visits had paraclinical tests performed and led to an admission in Bern than in Lausanne.

\section{Proportion and characteristics of low-acuity PED visits}

A total of 28556 among 53089 visits met our criteria for low acuity, representing $54 \%$ of all PEDs visits.

Children visiting our PEDs for low-acuity reasons were significantly younger than those visiting for high-acuity reasons (median 3.2 years, IQR $0.42-6$ vs 5 years, IQR $0.67-9.33, \mathrm{p}<0.001)$. Figure 1 shows that the proportion of low-acuity visits is higher among younger age categories ( 1 month to 5 years). There was no difference between genders. There was a higher proportion of patients living in proximity to the PED among lowacuity visits compared with high-acuity visits (table 2). There were fewer PED visits at night but children visiting at night were more likely to visit for a low-acuity reason. Figure 2 shows the volume of visits and the proportion of low-acuity visits per hour of the day. In the multivariable analysis, the adjusted odds of a PED visit to be a lowacuity visit were 1.27 (95\% CI 1.22 to 1.32 ) times higher for patients living in proximity to PED and 1.18 (95\% CI 1.13 to 1.23 ), 1.30 (95\% CI 1.23 to 1.36 ) and $1.14(95 \%$ CI 1.10 to 1.18), times higher for visits taking place in the evening, at night and during weekends, respectively.

A higher proportion of PED visits met our criteria for low acuity in Lausanne than in Bern, where triage was more frequently acute and more laboratory and imaging tests were performed.

Using only triage (ATS 4 and 5) to define low acuity led to a higher estimate of low-acuity PED visits (77\%). With this simpler definition, the proportion of children older than 5 years visiting for low-acuity reason was higher.

The analysis repeated excluding neonates younger than 1 month led to the same conclusions as the main analysis.

\section{DISCUSSION}

We found that low-acuity PEDs visits are frequent in Switzerland, accounting for 54\% of all PED visits. Families of younger children, those living close to the PED and those visiting outside business hours were more likely to consult for low-acuity reasons.

\section{Implications and outlook}

The results of this study point to a need for paediatric urgent care services, which are currently not covered by the primary care landscape in Switzerland. Though improvement of anticipatory guidance during routine primary care encounters may reduce after-hour PED consultations, ${ }^{1617}$ these educational strategies are unlikely to respond to the demand for urgent care services as many children visiting the PED for a low-acuity reason 


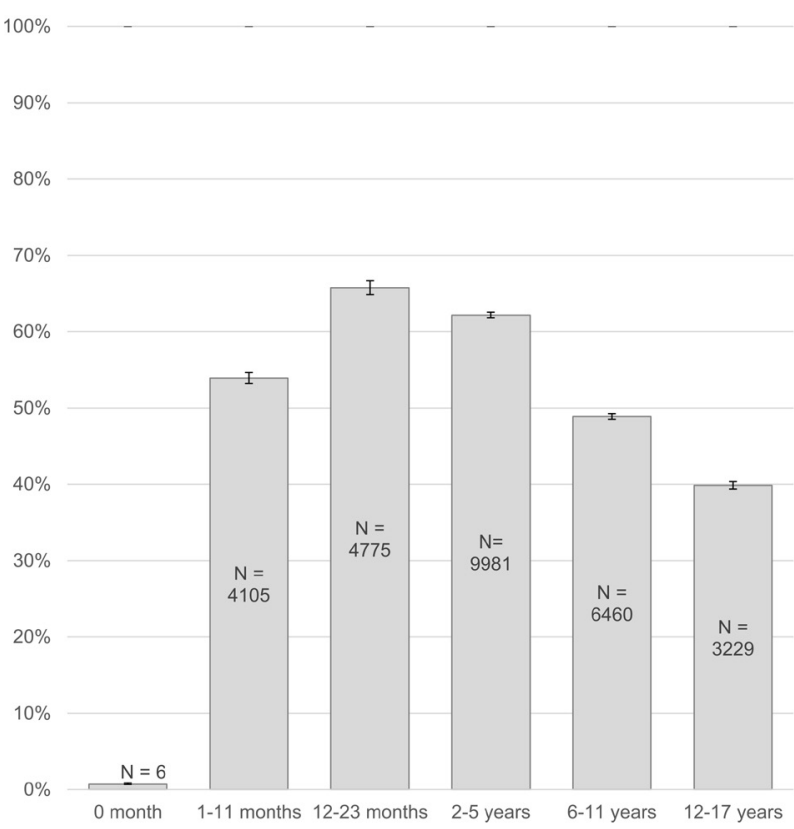

Figure 1 Proportion of low-acuity PED visits per age categories. Error bars show $95 \%$ Cls. Visits of neonates (younger than 1 month) should get by definition an urgent triage (ATS 1-3). Nevertheless, 7 out of 849 visits of neonates were classified by the nurse as triage level 4 or 5 . Among them one visit led to an admission and was classified as high-acuity visit. ATS, Australasian Triage Scale; PED, paediatric emergency department.

still need to be cared for by a healthcare provider. The large proportion of low-acuity PED visits happening in the evenings when PEDs are the only healthcare resources available (figure 2) might simply show that some families cannot visit their paediatrician during office hours. Access to medical advice and parental education as well as the importance of the role of paediatricians as the coordinators of patient care must be reinforced to ensure that paediatric care is delivered in time by the most appropriate healthcare provider. Our study provides a basis to develop solutions to address this issue. Possible solutions could include designated urgent care clinics, integrated within existing primary care structures or the PED. In designing such services, convenience factors such as proximity and after-hour services must be considered. Further research will be needed to better understand care seeking behaviour and vulnerable populations.

\section{Comparison with other studies}

In Switzerland, low-acuity ED visits have only studied been in the adult population, ${ }^{18} 19$ where they constituted approximately one-third of all ED visits with an increase over the time. For paediatrics, reported proportion of low-acuity PED visits varies between studies depending on the setting and on the criteria used to define low acuity. A systematic review on the proportion of non-urgent PED visits found a mean proportion of $41 \%$, ranging from $12 \%$ to $65 \% .{ }^{12}$ Similar to other studies, we found that younger age, proximity and after hour visits were associated with low-acuity PED visit. ${ }^{20-22}$ Other reported factors, such as regular primary care follow-up and parental socioeconomic status, could not be examined in our study. ${ }^{23-25}$ However, most children have regular paediatric follow-up in Switzerland. ${ }^{4}$

\section{Terminology and definition of low-acuity PED visits}

There is no consensus on a terminology nor a definition to describe the necessity for a PED visit (in contrast to health problems that could be attended by primary care specialists). ${ }^{12}$ These visits have been labelled with different terms in the literature, for example non-urgent, minor illnesses, inappropriate or low acuity. ${ }^{2022} 26$ We chose to define our outcome as 'low-acuity', which combines the level of urgency (triage scale) and complexity (resource use). Resource use, in addition to triage scale, reflects the need for specialised services that may not be available at primary care offices (in Switzerland, primary care offices often only have basic laboratory and imaging services at hand and not all offices are equipped to manage surgical cases).

Table 2 Characteristics of low-acuity and high-acuity PED visits from logistic regression model adjusted for all covariables

\begin{tabular}{|c|c|c|c|c|}
\hline Characteristics & $\begin{array}{l}\text { Low-acuity PED visits, } \\
\mathrm{n}=28556\end{array}$ & $\begin{array}{l}\text { High acuity PED visits, } \\
\mathrm{n}=24533\end{array}$ & P value* & Adjusted OR (95\% Cl) \\
\hline Age $\leq 5$ years & $18857(66 \%)$ & $12910(53 \%)$ & $<0.001 \dagger$ & $1.87(1.81$ to 1.94$)$ \\
\hline Gender: female & $12988(45 \%)$ & $11213(46 \%)$ & $0.607 \dagger$ & 1.00 (0.96 to 1.03$)$ \\
\hline Week-end visits & $9412(33 \%)$ & $7244(30 \%)$ & $<0.001 \dagger$ & 1.14 (1.10 to 1.18$)$ \\
\hline Evening visits (18:00-21:00 hours) & $7892(28 \%)$ & $6487(26 \%)$ & $0.002 \dagger$ & 1.18 (1.13 to 1.23$)$ \\
\hline Night visits (22:00-8:00 hours) & $5319(19 \%)$ & $3876(16 \%)$ & $<0.001 \dagger$ & 1.30 (1.23 to 1.36$)$ \\
\hline Residency $\leq 5 \mathrm{~km}$ from PED & $17871(63 \%)$ & $12241(50 \%)$ & $<0.001 \dagger$ & $1.27(1.22$ to 1.32$)$ \\
\hline Site: Lausanne & $19490(68 \%)$ & $12029(49 \%)$ & $<0.001 \dagger$ & 2.22 (2.13 to 2.30$)$ \\
\hline
\end{tabular}

Definition of low-acuity visits: Triage ATS 4 or 5 , no laboratory nor imaging tests and no hospital admission

${ }^{*} P$ value for comparison of acuity.

†Pearson's $\chi^{2}$ test.

ATS, Australasian Triage Scale; PED, paediatric emergency department. 


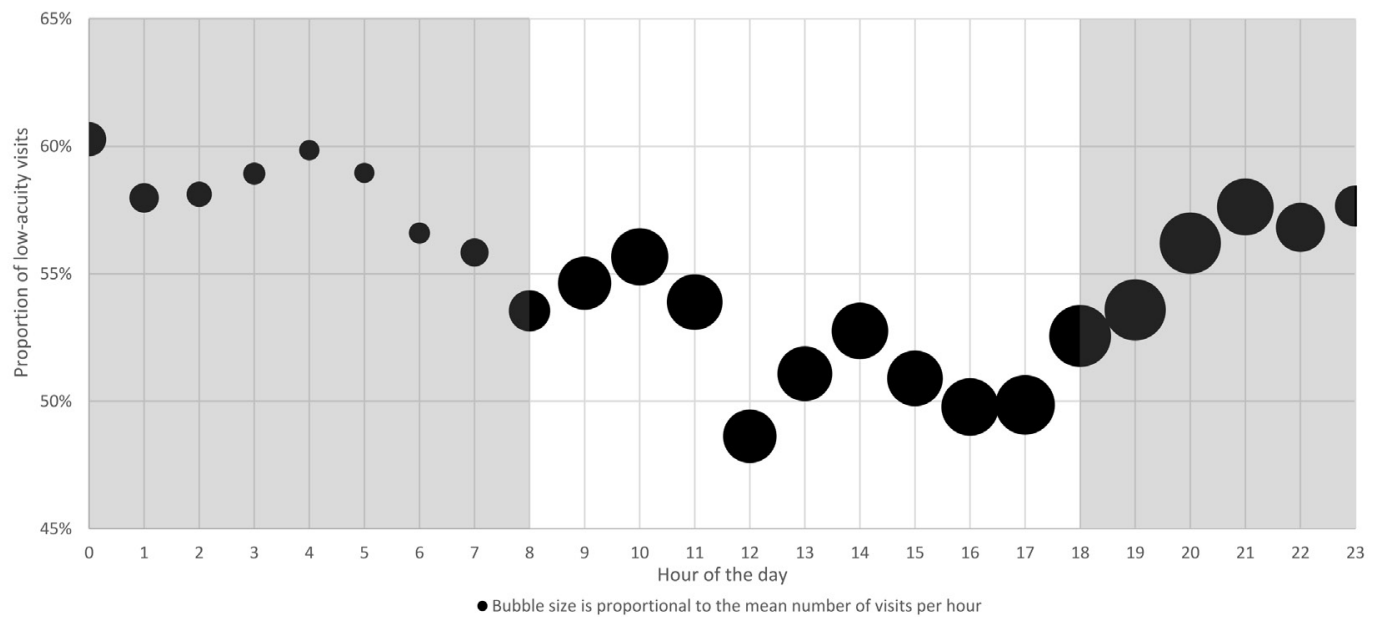

Figure 2 Proportion of low-acuity visits and number of visits per hour of the day. Shaded areas represent time outside business hours (evening time and night-time).

In a survey on the categorisation of PED visit urgency including paediatric emergency physicians, it was agreed that resource utilisation and nurse triage are preferred to determine the urgency of a PED visit when limited data are available, although complete medical record review is preferred. ${ }^{27}$ In practice, the definition of low-acuity used has varied among studies. Most studies used only triage to define visit acuity while some included resource utilisation and disposition. Only few used final diagnosis or physician chart review. Few studies use a combination of any of these factors. Physician charts review is time consuming and not realistically feasible for thousands of records. Diagnoses are often not standardised and, even when they are, they may not reflect urgency or complexity at the time of visit. Our definition uses readily standardised routine clinical data that can be extracted from clinical information system, allowing the analysis of a large amount of records while including multiple clinical parameters.

\section{Strengths and limitations}

The strengths of this study include the size of the dataset including all PED visits over an entire year in two of the five tertiary-care paediatric hospitals in Switzerland. They are located in two different regions of Switzerland and cover approximately $40 \%$ of the PED catchment area. The two PED did not have the same proportion of lowacuity visits, reflecting the differences in organisation of PED and in local practices. Whereas many studies used only triage as a proxy for acuity, we used a more comprehensive definition of low-acuity PED visits. Using only triage as a proxy for acuity would have led to a higher estimate of the number of low-acuity visits, especially among older children.

Our study has several limitations. First, this study was conducted in a tertiary-care setting and its results may not be generalisable to non-academic regional PEDs. Second, we could not identify surgical procedures performed in the PEDs because of the lack of standardised documentation in the electronic information systems. These visits may have been misclassified as low-acuity though they required PED services, as per our definition visits where small interventions were performed without paraclinical tests or hospital admission and low triage level were classified as low-acuity visits. Third, this study does not include data about final diagnosis. Ambulatory diagnoses are not coded in our PEDs and are documented in free text. However, we think that information on the final diagnosis alone is not sufficient to discriminate between high-acuity and low-acuity visits as some children with a minor illness appear moderately to severely ill and necessitate prompt paediatric evaluation to rule out major illness. Fourth, there is a systematic error regarding the association of young age and low-acuity visits. Neonates (younger than a month of age) get by definition an ATS level of 3 or less, which means that all visits of neonates in our population were classified as high-acuity visits. Yet, only a small fraction of visits was for neonates $(n=849,2 \%)$, and the analysis repeated with the exclusion of neonates lead to the same conclusions.

\section{CONCLUSION}

Low-acuity PEDs visits are frequent in Switzerland, a country where most children have a regular follow-up by a primary care paediatrician. Low-acuity visits were associated with younger age of the child and convenience factors. Further research is needed to improve urgent care services in Switzerland, considering care seeking behaviour and vulnerable populations.

\section{Author affiliations}

${ }^{1}$ Department Women-Mother-Child, Service of Pediatrics, Lausanne University Hospital and University of Lausanne, Lausanne, Switzerland

${ }^{2}$ Emergency Medicine, Department of Pediatrics, Inselspital, Bern University Hospital, University of Bern, Bern, Switzerland 
${ }^{3}$ Centre for Primary Care and Public Health (Unisanté), University of Lausanne, Lausanne, Switzerland

${ }^{4}$ Institute of Social and Preventive Medicine (ISPM), University of Bern, Bern, Switzerland

\section{Twitter Carl Starvaggi @CarlStarvagg}

Acknowledgements We thank Amagoia Madina (Unité de Valorisation des Données, Lausanne University Hospital) and the Insel Data Science Centre (IDSC, Inselspital) for the extraction of the data from the clinic information systems. We thank the SwissPedData team from the Institute of Social and Preventive Medicine, University of Bern for the support in the design of the study.

Contributors CEK, J-CS, KK, MG, MJ and RP conceptualised and designed the study. CS and MJ cleaned the data. J-CS and MJ performed the data analysis. MJ drafted the initial manuscript. All authors reviewed and revised the manuscript, and approved the final submitted manuscript. As guarantor, MJ.

Funding This work was supported by Fondation de l'Hôpital de l'Enfance (grant/ award number: Not applicable) and the Public Health Authorities of Canton de Vaud (grant/award number: Not applicable).

Competing interests None declared.

Patient consent for publication Not applicable.

Ethics approval This study was approved by the Cantonal Research Ethics Committees of Cantons of Vaud and Bern (project number 2019-00538).

Provenance and peer review Not commissioned; externally peer reviewed.

Data availability statement Data are available on reasonable request. Deidentified data are available on reasonable request and in compliance with ethical and legal requirements.

Supplemental material This content has been supplied by the author(s). It has not been vetted by BMJ Publishing Group Limited (BMJ) and may not have been peer-reviewed. Any opinions or recommendations discussed are solely those of the author(s) and are not endorsed by BMJ. BMJ disclaims all liability and responsibility arising from any reliance placed on the content. Where the content includes any translated material, BMJ does not warrant the accuracy and reliability of the translations (including but not limited to local regulations, clinical guidelines, terminology, drug names and drug dosages), and is not responsible for any error and/or omissions arising from translation and adaptation or otherwise.

Open access This is an open access article distributed in accordance with the Creative Commons Attribution Non Commercial (CC BY-NC 4.0) license, which permits others to distribute, remix, adapt, build upon this work non-commercially, and license their derivative works on different terms, provided the original work is properly cited, appropriate credit is given, any changes made indicated, and the use is non-commercial. See: http://creativecommons.org/licenses/by-nc/4.0/.

ORCID iD

Manon Jaboyedoff http://orcid.org/0000-0002-0063-1510

\section{REFERENCES}

1 Riva B, Clavenna A, Cartabia M, et al. Emergency department use by paediatric patients in Lombardy region, Italy: a population study. BMJ Paediatr Open 2018;2:e000247.

2 Burokienè S, Raistenskis J, Burokaitė E, et al. Factors determining parents' decisions to bring their children to the pediatric emergency department for a minor illness. Med Sci Monit 2017;23:4141-8.

3 Alele FO, Callander EJ, Emeto TI, et al. Socio-economic composition of low-acuity paediatric presentation at a regional hospital emergency department. J Paediatr Child Health 2018;54:1341-7.
4 Jenni OG, Sennhauser FH. Child health care in Switzerland. $J$ Pediatr 2016;177S:S203-12.

5 Vilpert S. Consultations dans un service d'urgence en Suisse. Neuchâtel Obs Suisse Santé2013.

6 Holm L, Fitzmaurice L. Factors influencing parent anxiety levels in a pediatric emergency department waiting area. Pediatr Res 2004;56:672.

7 Parkinson GW, Gordon KE, Camfield CS, et al. Anxiety in parents of young febrile children in a pediatric emergency department: why is it elevated? Clin Pediatr 1999;38:219-26.

8 Timm NL, Ho ML, Luria JW. Pediatric emergency department overcrowding and impact on patient flow outcomes. Acad Emerg Med 2008;15:832-7.

9 Miró O, Antonio MT, Jiménez S, et al. Decreased health care quality associated with emergency department overcrowding. European Journal of Emergency Medicine 1999;6:105-7.

10 Lutz N, Vandermensbrugghe NG, Dolci M, et al. Pediatric emergencies admitted in the resuscitation room of a Swiss university hospital. Pediatr Emerg Care 2014;30:699-704.

11 Svantner J, Dolci M, Heim C, et al. Pediatric trauma. Pediatr Emerg Care 2019; Publish Ahead of Print.

12 Alele FO, Emeto TI, Callander EJ, et al. Non-urgent paediatric emergency department presentation: a systematic review. J Paediatr Child Health 2019;55:271-7.

13 The Australasian triage scale. Emerg Med Australas 2002;14:335-6.

14 Williams A, O'Rourke P, Keogh S. Making choices: why parents present to the emergency department for non-urgent care. Arch Dis Child 2009;94:817-20.

15 Gafforini S, Turbitt E, Freed GL. Lower urgency paediatric injuries: parent preferences for emergency department or general practitioner care. Emerg Med Australas 2016;28:564-8.

16 Chang LC, Huang MC. Efficacy of scenario simulation-based education in relieving parental anxiety about fever in children. $J$ Pediatr Nurs 2021;61:102-8.

17 Thompson AP, Nesari M, Hartling L, et al. Parents' experiences and information needs related to childhood fever: a systematic review. Patient Educ Couns 2020;103:750-63.

18 Diserens L, Egli L, Fustinoni S, et al. Emergency department visits for non-life-threatening conditions: evolution over 13 years in a Swiss urban teaching hospital. Swiss Med Wkly 2015;145:w14123.

19 Bardelli P, Kaplan V. Non-Urgent encounters in a Swiss medical emergency unit. Swiss Med Wkly 2013;143:w13760.

20 Benahmed N, Laokri S, Zhang WH, et al. Determinants of nonurgent use of the emergency department for pediatric patients in 12 hospitals in Belgium. Eur J Pediatr 2012;171:1829-37.

21 Valent F, Busolin A. Distance to the pediatric emergency department and Nonurgent visits in Friuli Venezia Giulia, Italy. Pediatr Emerg Care 2018;34:193-7.

22 Vedovetto A, Soriani N, Merlo E, et al. The burden of inappropriate emergency department pediatric visits: why Italy needs an urgent reform. Health Serv Res 2014;49:1290-305.

23 Alele FO, Callander EJ, Emeto TI, et al. Socio-economic composition of low-acuity paediatric presentation at a regional hospital emergency department. J Paediatr Child Health 2018;54:1341-7.

24 Brousseau DC, Hoffmann RG, Nattinger AB, et al. Quality of primary care and subsequent pediatric emergency department utilization. Pediatrics 2007;119:1131-8.

25 Morrison AK, Schapira MM, Gorelick MH, et al. Low caregiver health literacy is associated with higher pediatric emergency department use and nonurgent visits. Acad Pediatr 2014:14:309-14.

26 Long CM, Mehrhoff C, Abdel-Latief E, et al. Factors influencing pediatric emergency department visits for low-acuity conditions. Pediatr Emerg Care 2018; Publish Ahead of Print.

27 Brousseau DC, Mistry RD, Alessandrini EA. Methods of categorizing emergency department visit urgency: a survey of pediatric emergency medicine physicians. Pediatr Emerg Care 2006;22:635-9. 